\title{
Estimating Longwave Net Radiation at Sea Surface from the Special Sensor Microwave/Imager (SSM/I)
}

\author{
Quanhua Liu, Clemens Simmer, and Eberhard Ruprecht \\ Institute for Marine Sciences, Kiel, Germany \\ (Manuscript received 18 March 1996, in final form 24 December 1996)
}

\begin{abstract}
A neural network is used to calculate the longwave net radiation $\left(L_{\mathrm{net}}\right)$ at the sea surface from measurements of the Special Sensor Microwave/Imager (SSM/I). The neural network applied in this study is able to account largely for the nonlinearity between $L_{\text {net }}$ and the satellite-measured brightness temperatures (TB). The algorithm can be applied for instantaneous measurements over oceanic regions with the area extent of satellite passive microwave observations (30-60 km in diameter). Comparing with a linear regression method the neural network reduces the standard error for $L_{\text {net }}$ from 17 to $5 \mathrm{~W} \mathrm{~m}^{-2}$ when applied to model results. For clear-sky cases, a good agreement with an error of less than $5 \mathrm{~W} \mathrm{~m}^{-2}$ for $L_{\text {net }}$ between calculations from SSM/I observations and pyrgeometer measurements on the German research vessel Poseidon during the International Cirrus Experiment (ICE) 1989 is obtained. For cloudy cases, the comparison is problematic due to the inhomogenities of clouds and the low and different spatial resolutions of the SSM/I data. Global monthly mean values of $L_{\text {net }}$ for October 1989 are computed and compared to other sources. Differences are observed among the climatological values from previous studies by H.-J. Isemer and L. Hasse, the climatological values from R. Lindau and L. Hasse, the values of W. L. Darnell et al., and results from this study. Some structures of $L_{\text {net }}$ are similar for results from W. L. Darnell et al. and the present authors. The differences between both results are generally less than $15 \mathrm{~W}$ $\mathrm{m}^{-2}$. Over the North Atlantic Ocean the authors found a poleward increase for $L_{\text {net }}$, which is contrary to the results of H.-J. Isemer and L. Hasse.
\end{abstract}

\section{Introduction}

Longwave net radiation over oceanic areas is an important component of the surface energy budget, which determines the interaction between ocean and atmosphere. Bulk formulas are often applied (e.g., Anderson 1952) to calculate the longwave net radiation at the sea surface from measured sea surface temperature, air temperature, humidity of the boundary layer, and cloud coverage. Gilman and Garrett (1994) discussed eight bulk formulas and found that the resulting annual mean difference of $L_{\text {net }}$ over the Mediterranean Sea can be up to $20 \mathrm{~W} \mathrm{~m}^{-2}$. They give also the uncertainty for the longterm averaged estimate of fluxes at the sea surface by using the bulk formulas. The uncertainty is $5 \mathrm{~W} \mathrm{~m}^{-2}$ for the solar radiation, $10 \mathrm{~W} \mathrm{~m}^{-2}$ for longwave radiation, $15 \mathrm{~W} \mathrm{~m}^{-2}$ for the latent flux, and $4 \mathrm{~W} \mathrm{~m}^{-2}$ for the sensible heat flux, which leads to an error for the total net flux of about $20 \mathrm{~W} \mathrm{~m}^{-2}$. The reported standard error for $L_{\text {net }}$ from bulk formulas compared to direct methods is $10-15 \mathrm{~W} \mathrm{~m}^{-2}$ for clear sky (Fung et al. 1984); for cloudy atmospheres the error becomes larger and the

Corresponding author address: Dr. Quanhua Liu, Institute for Marine Sciences, Düsternbrooker Weg 20, 24105 Kiel, Germany.

E-mail: qliu@awi-bremerhaven.de accuracy depends also on cloud types. In addition, few measurements of sea surface temperature, air temperature and humidity of the boundary layer, and of cloud coverage are available over oceanic areas. Therefore, calculating $L_{\text {net }}$ from satellite observations becomes an interesting topic. Gupta (1989) uses the International Satellite Cloud Climatology Project (ISCCP) dataset to determine $L_{\text {net }}$. Zhi and Harshvardhan (1993) calculate $L_{\text {net }}$ from a combination of general circulation model cloud radiative forcing fields, cloud radiative forcing at the top of the atmosphere from ERBE (Earth Radiation Budget Experiment), TOVS (TIROS Operational Vertical Sounder) profiles, and sea surface temperatures on ISCCP C1 tapes. Smith and Woolf (1983) performed a linear regression analysis on 1200 radiosonde profiles to derive a relationship between the net surface longwave radiation and the infrared radiances computed for the VISSR (Visible Infrared Spin Scan Radiometer) Atmospheric Sounder (VAS) channels on the Geostationary Operational Environmental Satellites (GOES). They obtained a standard error of $9.7 \mathrm{~W} \mathrm{~m}^{-2}$ for clear and $21.4 \mathrm{~W} \mathrm{~m}^{-2}$ for cloudy atmospheres. The large error in the latter case is due to the fact that surface net longwave radiation and the satellite-measured infrared radiances for cloudy atmospheres are largely decoupled (Schmetz 1989).

Measurements from passive microwave radiometers 
provide a better way to calculate $L_{\text {net }}$ for both clear and homogeneous cloudy atmospheres because most clouds are semitransparent and detectable in the microwave range. The satellite-measured upwelling radiances over oceanic areas contain information about the downwelling radiances due to the high microwave reflectivity of the sea surface. It will be shown that the downwelling microwave radiance is linearly related to the polarization, that is, the difference between vertically and horizontally polarized radiances. The downwelling microwave radiances are highly correlated with $L_{\text {net }}$ because both depend mainly on temperature, water vapor, and cloud liquid water. In section 2 , we describe the theory for calculating the net longwave radiation over oceanic areas. In section 3, a neural network is introduced. In section 4 an algorithm is developed with a training dataset, and the algorithm is verified with simulations using independent radiosonde data. In section 5, comparisons are carried out between the surface measured $L_{\text {net }}$ and the retrievals using SSM/I measurements. In section 6 , we illustrate and discuss the global distribution of net longwave radiation over oceanic areas for October 1989 and we compare our results with other published estimates.

\section{Theory}

The longwave net radiation over oceanic areas can be written as

$$
L_{\text {net }}=\varepsilon_{\mathrm{IR}}\left(\sigma T_{s}^{4}-F_{\mathrm{IR}}^{d}\right),
$$

where $\varepsilon_{\mathrm{IR}}$ is the longwave emissivity of the sea surface and its value is commonly assumed to be 0.98 (e.g., Gilman and Carret 1994). The quantities $\sigma, T_{s}$, and $F_{\mathrm{IR}}^{d}$ are the Stefan-Boltzmann constant, the sea surface temperature, and the downwelling longwave radiation, respectively.

In the thermal infrared spectral range, scattering effects can be neglected for most applications. The scattering effects can also be neglected for nonprecipitating and light to moderate raining clouds in the microwave spectrum at low frequencies. The equation describing the monochromatic radiative transfer through the planeparallel atmosphere reads (Liou 1980):

$$
\mu \frac{d I(\delta, \mu)}{d \delta}=I(\delta, \mu)-B(T),
$$

with $I$ the radiance, $\mu=\cos (\theta), \theta$ the zenith angle, $B(T)$ the Planck function, $T$ the temperature, and $\delta$ the optical depth. The solution of (2) at the top of the atmosphere can be written by

$$
I_{\mathrm{IR}}=\tau_{\mathrm{IR}} \varepsilon_{\mathrm{IR}} B\left(T_{s}\right)+I_{\mathrm{IR}}^{u}+\tau_{\mathrm{IR}}\left(1-\varepsilon_{\mathrm{IR}}\right) I_{\mathrm{IR}}^{d}
$$

in the thermal infrared spectral range, and

$$
\begin{aligned}
& \mathrm{TB}_{v}=\mathrm{TB}^{u}+\tau_{\mathrm{MW}}\left[\varepsilon_{v} T_{s}+\left(1-\varepsilon_{v}\right) \mathrm{TB}^{d}\right] \\
& \mathrm{TB}_{h}=\mathrm{TB}^{u}+\tau_{\mathrm{MW}}\left[\varepsilon_{h} T_{s}+\left(1-\varepsilon_{h}\right) \mathrm{TB}^{d}\right]
\end{aligned}
$$

in the microwave spectral range, where the radiance has been substituted by the brightness temperature using Rayleigh-Jean's approximation. Here, $\tau$ is the total transmittance of the atmosphere. The quantities $I_{\mathrm{IR}}^{u}$ and $I_{\mathrm{IR}}^{d}\left(\mathrm{~TB}^{u}\right.$ and $\left.\mathrm{TB}^{d}\right)$ are the upwelling and downwelling radiances (brightness temperatures). The subscripts $v$ and $h$ denote the vertical and the horizontal polarizations, respectively. Here, $\varepsilon_{v}$ and $\varepsilon_{h}$ are the vertical and the horizontal components of the microwave sea surface emissivity, respectively. The downwelling longwave radiation $F_{\mathrm{IR}}^{d}$ is calculated as

$$
F_{\mathrm{IR}}^{d}=2 \pi \int_{0}^{1} \mu I_{\mathrm{IR}}^{d} d \mu .
$$

The downwelling radiance $I_{\mathrm{IR}}^{d}$ contributes very little to the measurements of satellite-based infrared radiometers because the thermal infrared emissivity of the sea surface $\varepsilon_{\mathrm{IR}}$ is close to 1 . This has been demonstrated by Ramanathan (1986), who compared the outgoing longwave radiative flux at the top of the atmosphere with the net longwave surface flux for selected regions from simulations with the National Center for Atmospheric Research (NCAR) general circulation model. The correlation between both fluxes is very poor. Because of the low microwave emissivity of the sea surface (about 0.5), microwave radiometers on satellites measure a mixed information containing contributions from the sea surface, the upwelling brightness temperature $\mathrm{TB}^{u}$, and the downwelling brightness temperature $\mathrm{TB}^{d}$. Here $\mathrm{TB}^{d}$ can be extracted by subtracting (3c) from (3b)

$$
\mathrm{TB}^{d}=T_{s}-\frac{\mathrm{TB}_{v}-\mathrm{TB}_{h}}{\tau_{\mathrm{MV}}\left(\varepsilon_{v}-\varepsilon_{h}\right)},
$$

where $\varepsilon_{v}$ and $\varepsilon_{h}$ are a function of the sea surface roughness caused by wind and the sea surface temperature. The total transmittance of the atmosphere $\tau_{\mathrm{MV}}$ is mainly a function of the total precipitable water, the cloud liquid water path, and precipitation (Greenwald et al. 1993; Petty 1994; Weng and Grody 1994; Wentz 1992). The sea surface wind, sea surface temperature, total water vapor, cloud liquid path, and rainwater can be determined from measurements of spaceborne microwave radiometers (Goodberlet et al. 1990; Crewell et al. 1991; Bauer and Schluessel 1993; Liu and Curry 1992). Thus, with the polarization $Q\left(Q=\mathrm{TB}_{v}-\mathrm{TB}_{h}\right)$ directly observable and all other parameters in (4) affecting microwave radiation in general, information about $\mathrm{TB}^{d}$ is also contained in the microwave signal at satellite altitudes.

The question is, how closely do the downwelling brightness temperatures relate to the downwelling thermal infrared fluxes. To investigate this relation, a set of oceanic radiosonde profiles were used as input to radiative transfer models (see section 4). Table 1 shows the correlation coefficients between $F_{\mathrm{IR}}^{d}$ and $\mathrm{TB}^{d}$ for the four Special Sensor Microwave/Imager (SSM/I) frequencies. In general, correlation coefficients for clear- 
TABLE 1. Correlation coefficients between the downwelling longwave radiation and the downwelling brightness temperature at sea surface. The downwelling longwave radiation and the downwelling brightness temperatures over oceanic areas are calculated with radiative transfer models from radiosonde data for 1989 .

\begin{tabular}{lcccc}
\hline \hline & $19.35 \mathrm{GHz}$ & $22.235 \mathrm{GHz}$ & $37 \mathrm{GHz}$ & $85.5 \mathrm{GHz}$ \\
\hline All cases & 0.81 & 0.90 & 0.59 & 0.82 \\
Clear-sky cases & 0.95 & 0.95 & 0.95 & 0.97 \\
\hline
\end{tabular}

sky cases are larger than for cloudy cases, especially at $37 \mathrm{GHz}$. The best correlation is found for clear-sky cases at $85 \mathrm{GHz}$ because this channel shows the best relation to the boundary layer humidity, which dominates $F_{\mathrm{IR}}^{d}$.

\section{Neural network}

To derive a retrieval algorithm for $L_{\text {net }}$ from satellitemeasured brightness temperatures, a neural network is applied. An artificial neural network solves the retrieval problem using a highly connected array of elementary processors called neurons. Each elementary processor performs a simple function (e.g., Tsang et al. 1992). We use a layered perceptron-type artificial neural network, which has one input layer, one or more hidden layers, and one output layer. Each layer employs several neurons and each neuron in the same layer is connected to neurons in the adjacent layer with different weights. The weights can be calculated from the backpropagation learning algorithm based on a training dataset. This backpropagation algorithm uses the gradient descent algorithm to get a local minimum between the calculated output and the actual output. The description of the neural network algorithm is referred to Hertz et al. (1991). Although the choice of hidden layers and neurons is arbitrary as long as the total number of weights is much smaller than the size of the training dataset, for our application we used seven neurons in the input layer representing seven SSM/I brightness temperatures, two hidden layers with five neurons each. Two hidden layers are usually applied in the field of remote sensing (e.g., Chen et al. 1995). Using more than five neurons for the present study gives only slightly better results. The output layer consists of one neuron representing $L_{\text {net }}$. If the brightness temperatures at $85 \mathrm{GHz}$ are not available, five neurons are used in the input layer.

\section{Algorithm development}

To derive the algorithm, we need values of the surface longwave radiation balance and passive microwave measurements from SSM/I at the same time. Such data do not exist. So we use simulated data instead. Because the developed method is statistical, we must base the simulated measurements on realistic atmospheric situations, which we obtained from ship-based radiosoundings. Clouds and precipitation are parameterized and radiative transfer models are used to simulate the sat- ellite radiances and the surface longwave radiation balance. From a global dataset of about 10000 ship-based radiosonde ascents of the whole year of 1989 (Fig. 1) obtained from the German Weather Service (DWD), we used six months (January, March, May, July, September, November) as a training dataset. The remaining six months are chosen for the validation. Temperature and moisture profiles are interpolated to 40 layers. The top level of the interpolated profile is $40 \mathrm{~km}$ above the sea surface. The cloud liquid water profile is analyzed from the profiles using the modified adiabatic liquid water approach (Karstens et al. 1994). This method computes the adiabatic liquid water for contiguous layers with relative humidities above $95 \%$. A height-dependent factor takes into account entrainment of dry air, precipitation, and freezing by scaling the liquid water profiles based on a parameterization obtained from aircraft measurements. It has been shown by Karstens et al. (1994) that this procedure produces realistic frequency distributions of total cloud liquid water contents and cloudtop heights. Cloud ice is determined for cloudy layers with temperatures below $-20^{\circ} \mathrm{C}$ according to the parameterization by Liou (1986). The parameterization is to fit the observed mean ice content as a function of temperature, that is, based on the fact that temperature is the predominant factor controlling the ice crystal size and the consequence of the ice content. The two-stream radiative transfer code by Schmetz (1986) is used to calculate the net sea surface longwave radiation. The two-stream code used here is composed of 51 intervals covering spectral range from 4 to $400 \mu \mathrm{m}$. The twostream approximation can achieve a quick approximate solution to the radiative transfer equation by decomposing the radiative field into two opposing streams (i.e., upward and downward streams). For the microwave radiation, polarization is required to be considered, which is beyond the capacity of the two-stream model. The matrix-operator method is one of the commonly used methods to account for the scattering and polarization. For a homogeneous layer, the matrix-operator-method solves the radiative transfer equation in analytical matrices. The solution of the radiative transfer equation for the vertically inhomogeneous atmosphere is obtained recurrently from the analytical solutions for a set of homogeneous layers, where the vertically inhomogeneous atmosphere is subdivided into a set of homogeneous layers. A matrix-operator radiative transfer code (Liu and Ruprecht 1996) is used to calculate the seven brightness temperatures at the top of the atmosphere for the SSM/I frequencies $(19.35 \mathrm{GHz}, 37 \mathrm{GHz}, 85.5 \mathrm{GHz}$ both vertically and horizontally polarized; $22.235 \mathrm{GHz}$ only vertically polarized). The absorption coefficients of gases in the microwave spectrum are adopted from Liebe (1985). The parameterization of Wisler and Hollinger (1977) is used to model the reflection and emission of the sea surface in the microwave spectrum. For a given frequency, the parameterization of Wisler and Hollinger (1977) needs the sea surface temperature and 


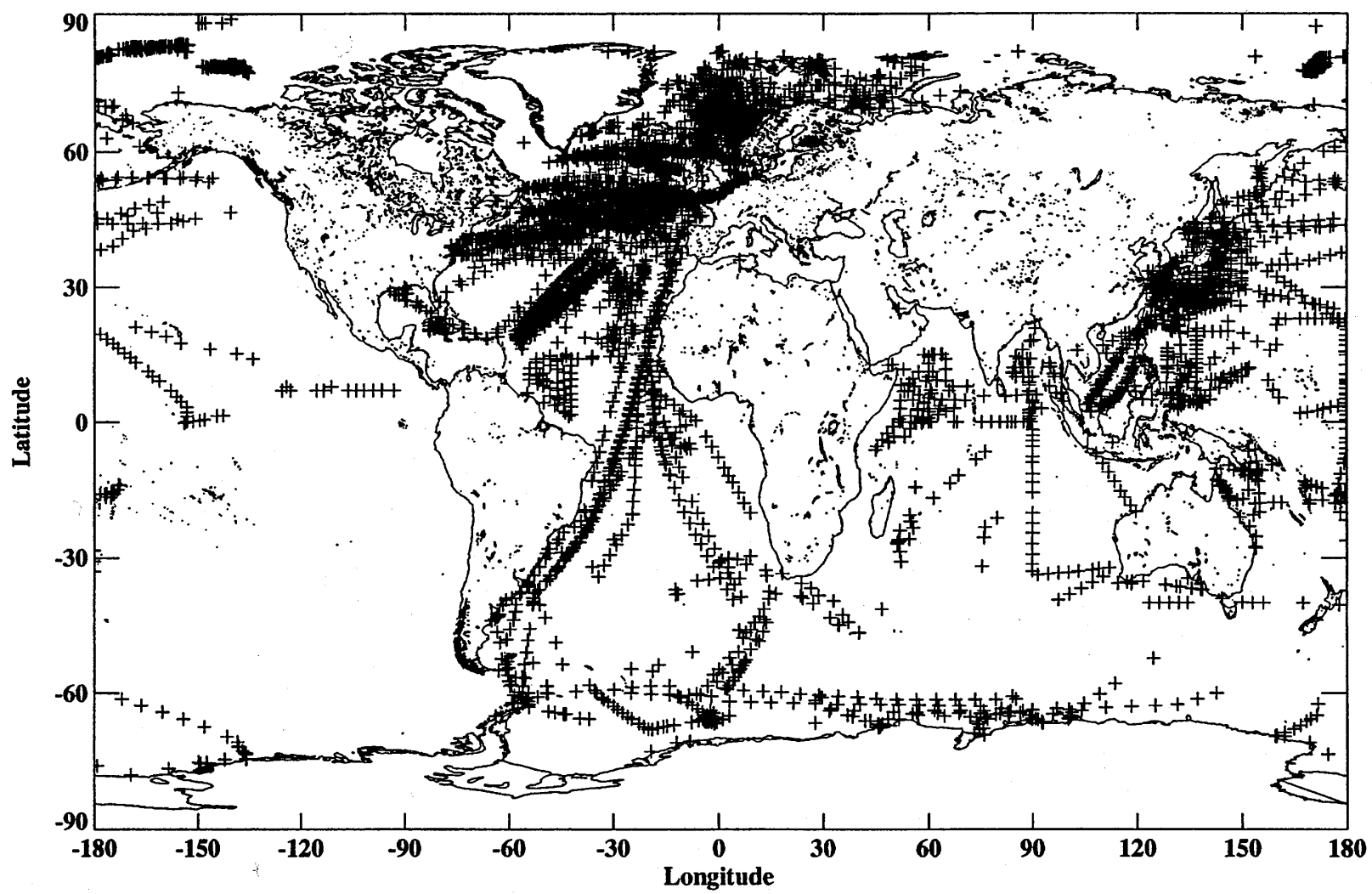

FIG. 1. Distributions of the available radiosonde profiles over oceanic areas for 1989 used in this study.

the salinity to calculate the dielectric constant. The effects of surface roughness and possible foam are parameterized as functions of the sea surface wind speed. Stability is not taken into account, thus a single relation between wind speed and wind stress is assumed. In this study, salinity is set to thirty per thousand for all cases, because in the frequency range of SSM/I the effect of its variability is negligible. For clouds all particles are

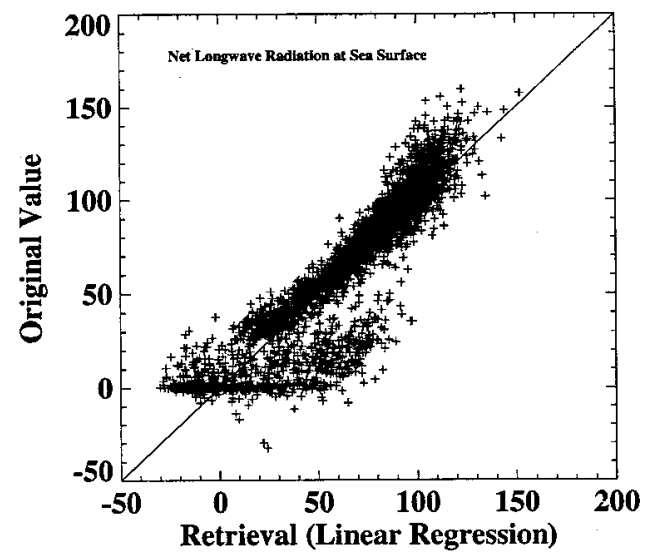

FIG. 2. Comparison of $L_{\text {net }}\left(\mathrm{W} \mathrm{m}^{-2}\right)$ calculated from radiative transfer model with $L_{\text {net }}$ estimated from modeled SSM/I brightness temperatures (retrieval algorithm derived by a linear regression method). assumed to be spherical particles. Marshall-Palmer distribution is used to describe the size spectrum of ice clouds and rain clouds. The phase matrix, extinction, and scattering coefficients are calculated with a Mie code. At first, we use the following linear regression equation to calculate $L_{\text {net }}$ :

$$
\begin{aligned}
L_{\text {net }}= & 479.5+5.338 \mathrm{~TB}_{19 \mathrm{H}}-2.837 \mathrm{~TB}_{19 \mathrm{H}}-11.701 \mathrm{~TB}_{37 \mathrm{~V}} \\
& +6.098 \mathrm{~TB}_{37 \mathrm{H}}+0.826 \mathrm{~TB}_{22 \mathrm{~V}}+4.011 \mathrm{~TB}_{85 \mathrm{~V}} \\
& -3.383 \mathrm{~TB}_{85 \mathrm{H}} .
\end{aligned}
$$

In Fig. 2, we compare for the independent dataset (February, April, June, August, October, December of 1989) the modeled $L_{\text {net }}$ with the retrieved values obtained by the linear regression on the basis of the modeled SSM/I brightness temperatures. The scatter is large (with a standard error of $17 \mathrm{~W} \mathrm{~m}^{-2}$ ), especially for cloudy cases where $L_{\text {net }}$ is small or negative. The large scatter can be reduced when a nonlinear technique, such as a neural network, is applied (Fig. 3). About 5000 atmospheric profiles are used to calculate $L_{\text {net }}$ and the seven simulated SSM/I brightness temperatures. The calculated seven brightness temperatures are used as inputs and the calculated $L_{\text {net }}$ is used as output to train the neural network. The structure and weights from the trained neural network can be finally applied to derive $L_{\text {net }}$ from brightness temperatures of either simulations 


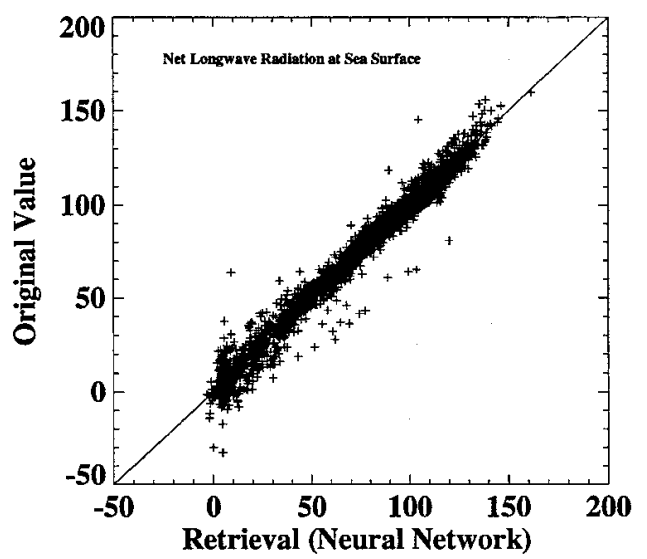

FIG. 3. Same as in Fig. 2 but using a neural network to derive the retrieval algorithm. or satellite measurements. For all cases the standard error is dramatically reduced from 17 to $5 \mathrm{~W} \mathrm{~m}^{-2}$. The algorithm is relatively stable. By introducing a positive uniformly distributed random error with an amplitude of $5 \mathrm{~K}$ on the sea surface temperature of the test data the standard error of the estimation of $L_{\text {net }}$ increases to $6.7 \mathrm{~W} \mathrm{~m}^{-2}$ when the weights in the neural network are kept the same as before. The bias by introducing the perturbation is very small $\left(0.4 \mathrm{~W} \mathrm{~m}^{-2}\right)$. In section 5 and 6 our retrievals for 1989 are shown. In that year the $85-\mathrm{GHz}$ channels were not functioning well, so the neural network was trained only with five channels. The retrieval error for the reduced input data is about 6.5 $\mathrm{W} \mathrm{\textrm {m } ^ { - 2 }}$.

It is known that the retrieval algorithms for atmospheric parameters are suffered from the cases of heavy rain. Fortunately, cases of heavy rain have little effect on the estimation of $L_{\text {net }}$ from SSM/I data because the polarization difference is very small for those cases. This results also in small values for $L_{\text {net }}$, which we would expect under such conditions.

TABLE 2. Samples of measured and calculated $L_{\text {net }}$, satellite data, and the temporal and spatial differences in the simulations.

\begin{tabular}{|c|c|c|c|c|c|c|c|c|c|c|}
\hline $\begin{array}{l}\text { Date } \\
\text { Time }\end{array}$ & $\begin{array}{l}\text { Temporal } \\
\text { difference } \\
\quad(\mathrm{min})\end{array}$ & $\begin{array}{c}\text { Spatial } \\
\text { difference } \\
(\mathrm{km})\end{array}$ & $\begin{array}{c}\mathrm{TB}_{19 \mathrm{~V}} \\
(\mathrm{~K})\end{array}$ & $\begin{array}{c}\mathrm{TB}_{19 \mathrm{H}} \\
(\mathrm{K})\end{array}$ & $\begin{array}{c}\mathrm{TB}_{37 \mathrm{~V}} \\
(\mathrm{~K})\end{array}$ & $\begin{array}{c}\mathrm{TB}_{37 \mathrm{H}} \\
(\mathrm{K})\end{array}$ & $\begin{array}{c}\mathrm{TB}_{22 \mathrm{~V}} \\
(\mathrm{~K})\end{array}$ & $\begin{array}{c}\text { Estimated } \\
L_{\mathrm{net}} \\
\left(\mathrm{W} \mathrm{m}^{-2}\right)\end{array}$ & $\begin{array}{c}\text { Measured } \\
L_{\text {net }} \\
\left(\mathrm{W} \mathrm{m}^{-2}\right)\end{array}$ & \\
\hline $\begin{array}{l}2 \text { Oct } \\
0447 \\
2 \text { Oct }\end{array}$ & 19 & 7 & 192.0 & 131.2 & 219.1 & 173.5 & 209.1 & 16.8 & 38.2 & Cloud \\
\hline $\begin{array}{l}1834 \\
3 \text { Oct }\end{array}$ & 12 & 16 & 196.9 & 134.1 & 224.3 & 177.7 & 216.9 & 10.3 & 36.2 & Cloud \\
\hline $\begin{array}{l}0429 \\
3 \text { Oct }\end{array}$ & 87 & 47 & 188.4 & 122.0 & 212.0 & 155.3 & 208.3 & 39.0 & 42.4 & Cloud \\
\hline $\begin{array}{l}1832 \\
4 \text { Oct }\end{array}$ & 23 & 2 & 185.5 & 111.6 & 206.2 & 136.4 & 208.8 & 73.2 & 48.8 & Cloud \\
\hline $\begin{array}{l}0441 \\
5 \text { Oct }\end{array}$ & 62 & 16 & 189.1 & 119.9 & 211.6 & 149.3 & 211.5 & 44.9 & 67.6 & Cloud \\
\hline $\begin{array}{l}1842 \\
6 \text { Oct }\end{array}$ & 29 & 14 & 203.0 & 148.2 & 233.6 & 197.2 & 232.8 & 4.5 & 36.3 & Cloud \\
\hline $\begin{array}{l}0449 \\
6 \text { Oct }\end{array}$ & 37 & 7 & 183.2 & 113.7 & 203.4 & 139.0 & 199.8 & 112.2 & 114.7 & Clear \\
\hline $\begin{array}{l}1835 \\
8 \text { Oct }\end{array}$ & 12 & 7 & 188.1 & 120.7 & 207.0 & 148.5 & 203.2 & 87.4 & 106.1 & Cloud \\
\hline $\begin{array}{l}1825 \\
9 \text { Oct }\end{array}$ & 21 & 8 & 190.9 & 124.1 & 211.7 & 151.5 & 216.1 & 48.2 & 36.7 & Cloud \\
\hline $\begin{array}{l}1826 \\
10 \text { Oct }\end{array}$ & 7 & 1 & 188.0 & 117.8 & 211.2 & 154.3 & 201.5 & 40.7 & 54.1 & Cloud \\
\hline $\begin{array}{l}0425 \\
11 \text { Oct }\end{array}$ & 20 & 8 & 186.1 & 117.5 & 205.6 & 143.0 & 204.7 & 92.1 & 69.0 & Cloud \\
\hline $\begin{array}{l}1829 \\
12 \text { Oct }\end{array}$ & 23 & 51 & 197.0 & 136.9 & 226.3 & 181.0 & 221.3 & 7.7 & 47.4 & Cloud \\
\hline $\begin{array}{l}0438 \\
13 \text { Oct }\end{array}$ & 62 & 6 & 193.0 & 130.0 & 214.1 & 156.9 & 221.8 & 40.0 & 34.0 & Cloud \\
\hline $\begin{array}{l}1832 \\
15 \text { Oct }\end{array}$ & 50 & 11 & 186.9 & 120.3 & 204.8 & 146.2 & 202.9 & 105.0 & 102.5 & Clear \\
\hline $\begin{array}{l}0445 \\
17 \text { Oct }\end{array}$ & 17 & 7 & 182.9 & 113.3 & 204.7 & 142.2 & 199.3 & 83.8 & 85.7 & Clear \\
\hline $\begin{array}{l}0447 \\
17 \text { Oct }\end{array}$ & 11 & 5 & 191.5 & 126.1 & 209.0 & 149.3 & 217.1 & 74.3 & 72.1 & Clear \\
\hline $\begin{array}{l}1835 \\
18 \text { Oct }\end{array}$ & 5 & 3 & 190.1 & 122.2 & 208.9 & 146.2 & 214.3 & 71.5 & 20.7 & Cloud \\
\hline $\begin{array}{l}0446 \\
19 \text { Oct }\end{array}$ & 23 & 6 & 185.7 & 115.1 & 205.7 & 137.4 & 207.6 & 94.1 & 93.8 & Clear \\
\hline 0443 & 34 & 21 & 192.7 & 127.4 & 210.3 & 149.9 & 219.7 & 68.9 & 15.9 & Cloud \\
\hline
\end{tabular}




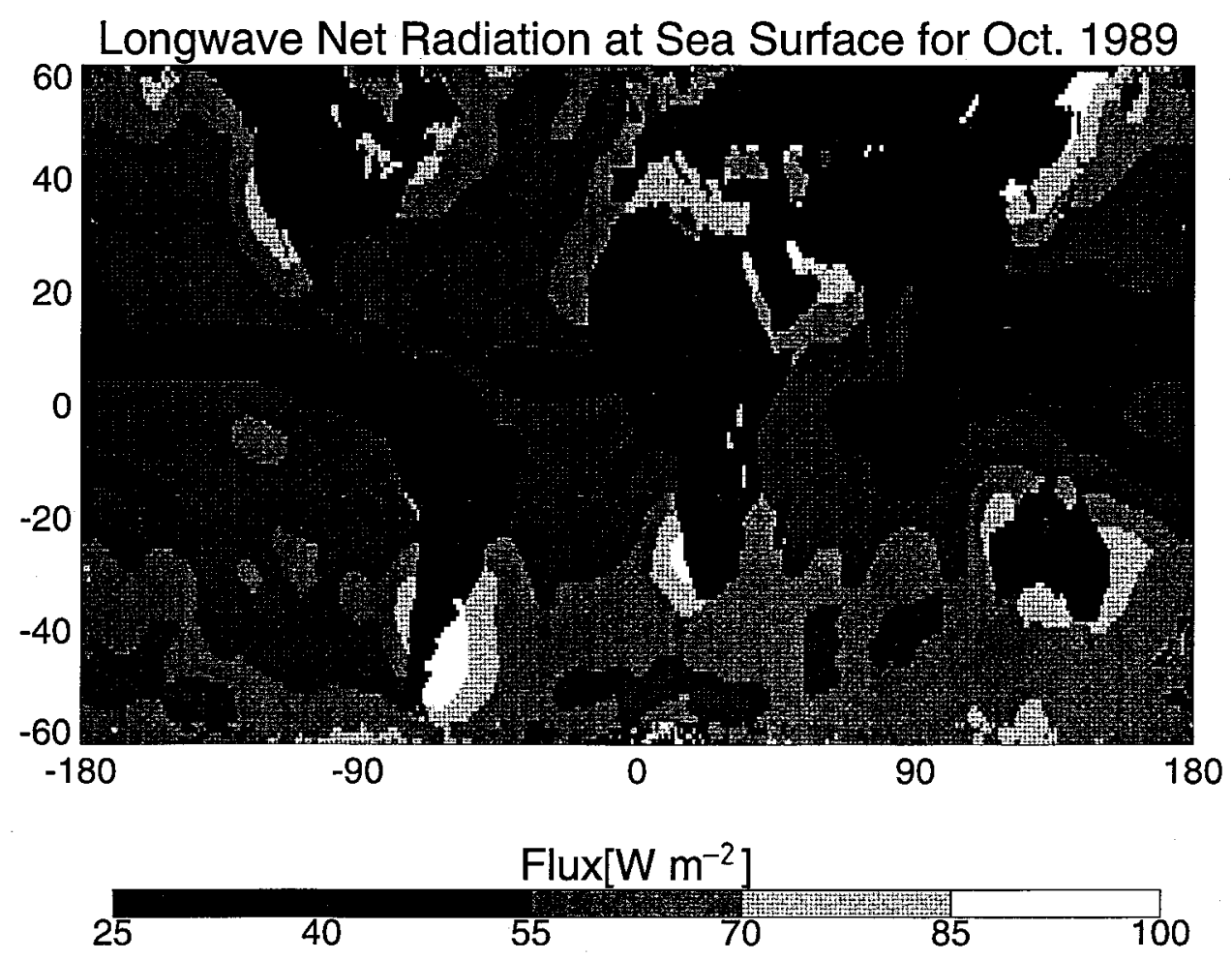

FIG. 4. Global monthly mean values of $L_{\text {net }}\left(\mathrm{W} \mathrm{m}^{-2}\right)$ calculated from SSM/I measurements by a neural network over oceanic areas for October 1989.

\section{Comparison with direct measurements}

There are few measurements of the longwave radiation flux available over oceans. It is even more difficult to obtain simultaneous measurements of $L_{\text {net }}$ from ship observations and radiances (or brightness temperatures) from satellite measurements. There is not yet a comprehensive in situ validation in this approach. The simultaneous data we obtained from our experiment was not sufficient to completely validate our algorithm. The comparison gives us some confidence in the performance of the algorithm. The satellite data used here is the SSM/I flying aboard the DMSP spacecraft series. The ground footprint of the SSM/I data is $69 \mathrm{~km} \times 43$ $\mathrm{km}$ at $19.35 \mathrm{GHz}, 37 \mathrm{~km} \times 29 \mathrm{~km}$ at $37 \mathrm{GHz}, 15 \mathrm{~km}$ $\times 13 \mathrm{~km}$ at $85.5 \mathrm{GHz}$, and $50 \mathrm{~km} \times 40 \mathrm{~km}$ at 22.235 GHz. The satellite overflew the North Sea at about 0400 in the morning and 1800 in the evening. The measurement data of $L_{\text {net }}$ was sampled during the International Cirrus Experiment (ICE) in October 1989. The ICE experiment was carried out by 70 scientists and students from Great Britain, France, Germany, and Sweden as a contribution to the ISCCP (Hennings et al. 1990). The radiosonde data, pyrgeometer measurements for the downwelling longwave radiation $F_{\mathrm{IR}}^{d}$ on the ship, and ship synoptic measurements were performed onboard the German research vessel Poseidon operating in the North Sea. The measured net longwave radiation $L_{\text {net }}$ is calculated from the pyrgeometer measured $F_{\mathrm{IR}}^{d}$ and the measured sea surface temperature. The accuracy of the pyrgeometer measurement is about $5 \mathrm{~W} \mathrm{~m}^{-2}$. The synoptic observation of clouds by the satellite pass over was not very reliable because it was dark and the variability of clouds was large. Clear sky is assumed when the synoptic observation is clear sky and the cloud liquid water path derived from SSM/I measurements (Karstens et al. 1994) is equal to $0 \mathrm{~g} \mathrm{~m}^{-2}$. During the 3 -weeklong ICE experiments in October 1989, only 5 simultaneous measurements for clear-sky cases and 14 simultaneous measurements for cloudy cases over North Atlantic were obtained. The spatial difference between the satellite and shipborne measurements were between 1 and $51 \mathrm{~km}$. The temporal differences between the satellite and shipborne measurements were between 5 and $87 \mathrm{~min}$. The time of the satellite pass over, the spatial and temporal differences between the satellite and shipborne measurements, the SSM/I brightness temperatures, the estimated $L_{\text {net }}$ from SSM/I measurements, the measured $L_{\text {net }}$, and the synoptic observation of clouds are given in Table 2. For clear-sky cases the retrieved values from SSM/I observations agree very well with the surface measurements. For cloudy cases a large standard error $\left(24 \mathrm{~W} \mathrm{~m}^{-2}\right)$ is observed, which is probably due to the spatial inhomogenity of clouds and possibly the different spatial resolutions of the different frequencies. For the cases of inhomogeneous clouds, the use of the microwave radiometer does not provide a 

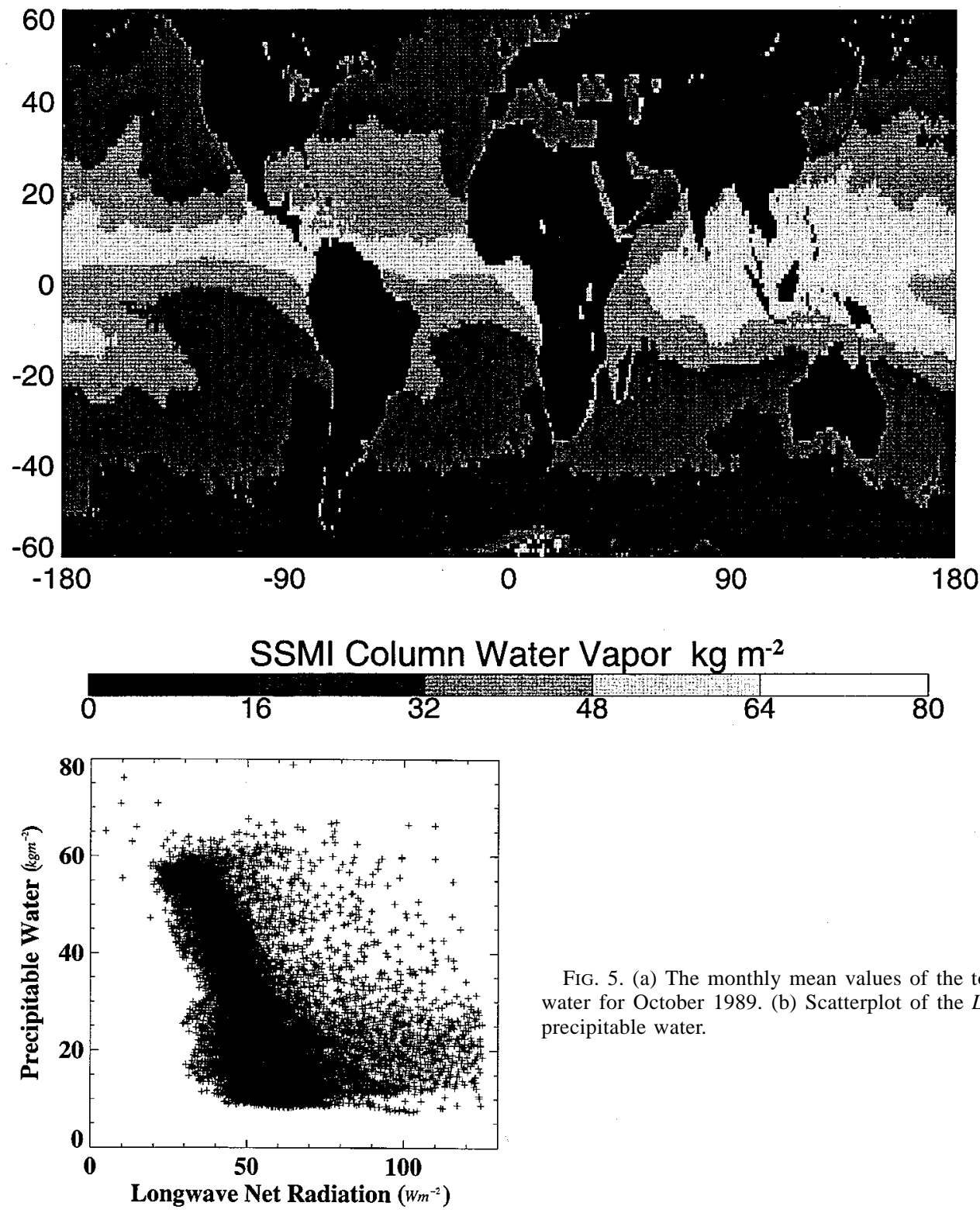

FIG. 5. (a) The monthly mean values of the total precipitable water for October 1989. (b) Scatterplot of the $L_{\text {net }}$ and the total precipitable water.

better estimation of $L_{\text {net }}$ than the use of the infrared radiometer, due to the poor and different spatial resolutions of the microwave radiometer and the three-dimensional radiative transfer effects (e.g., Haferman et al. 1996).

\section{Global distribution of $L_{\text {net }}$}

A global monthly mean $L_{\text {net }}$ computed from SSM/I F8 measurements for October 1989 is shown in Fig. 4. The values for latitudes higher than $60^{\circ} \mathrm{S}$ or $60^{\circ} \mathrm{N}$ are excluded to avoid possible sea ice contaminations. Low values are found as expected in the areas of high cloud coverage: maritime continent and intertropical conver- gence zone. In the commonly cloud-free regions over cold water the high values stand out. In general, an increase of $L_{\text {net }}$ toward the poles is observed. The total precipitable water has a high correlation with $L_{\text {net }}$. Due to its obvious relation to the downward longwave radiation, the total precipitable water $(\mathrm{PW})$ is also correlated with $L_{\text {net. }}$. We use the algorithm of Simmer (1994) to calculate the water vapor path over the ocean from the SSM/I dataset. The monthly mean values of the total precipitable water for October 1989 is given in Fig. 5a. It can be seen from Figs. 4 and 5 that the $L_{\text {net }}$ has an opposite distribution compared with the total precipitable water. The high (low) values of $L_{\text {net }}$ appear generally in the areas where the total precipitable water is low (high). A correlation coefficient between $L_{\text {net }}$ and 


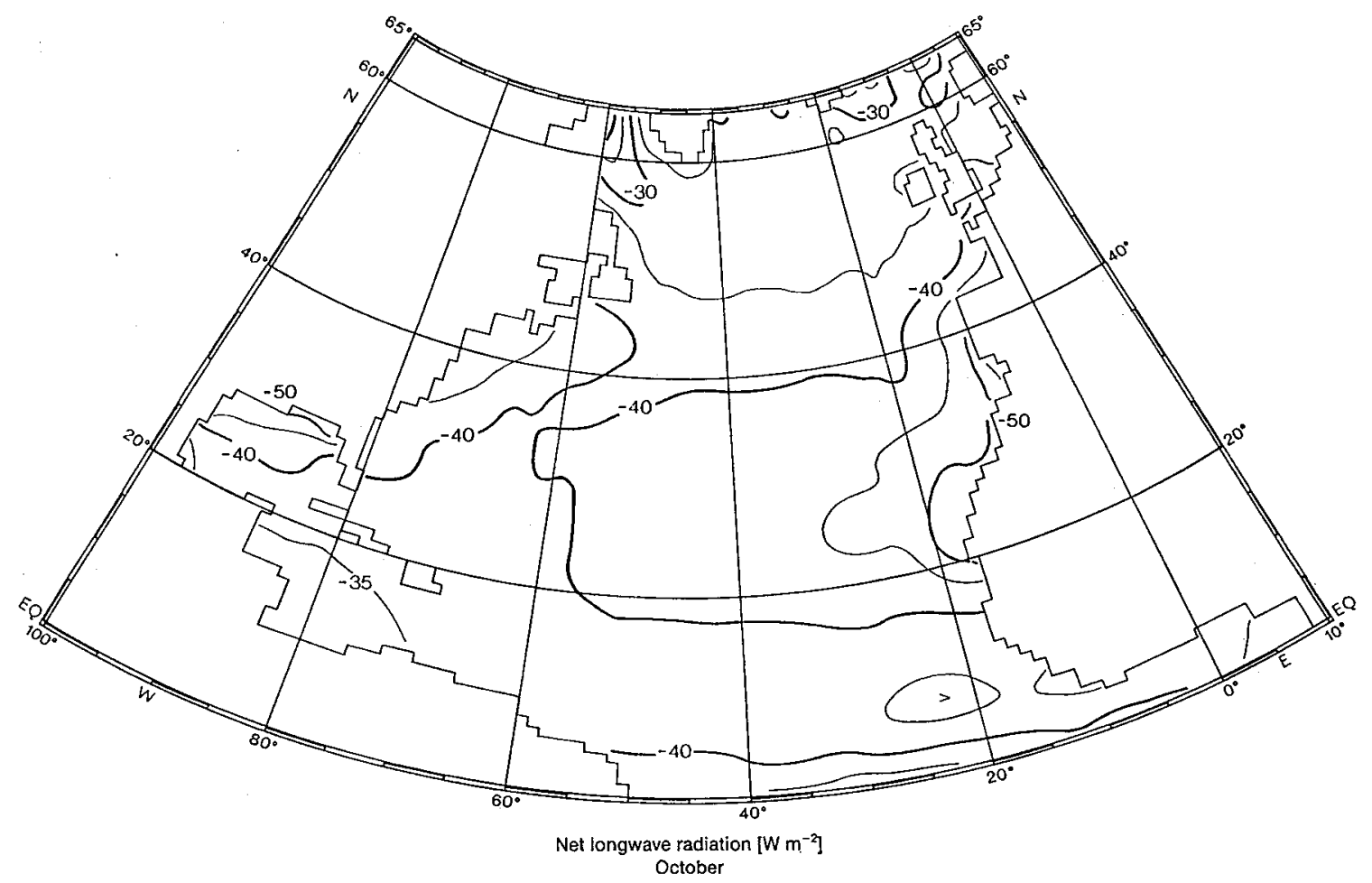

FIG. 6a. Climatological distribution of $L_{\text {net }}\left(\mathrm{W} \mathrm{m}^{-2}\right)$ for October over the North Atlantic Ocean (Isemer and Hasse 1985).

the total precipitable water is 0.6 (Fig. $5 b$ ), that is, $36 \%$ of the variability of $L_{\text {net }}$ can be explained by PW.

Differences are observed between these results and the long-term climatological distributions (Fig. 6a) for October over the North Atlantic Ocean from Isemer and Hasse (1985), who applied the bulk formula of Budyko (1974). Our values are higher over most areas. In contrast to our results, Isemer and Hasse (1985) found a decrease from the midlatitudes to the high latitudes. Recently, Lindau and Hasse (1997) used the Comprehensive Ocean Atmosphere Data Set (COADS) to calculate $L_{\text {net }}$ with the bulk formula from Bignami et al. (1991). Their results (Fig. 6b) agree much better with ours and they confirm the poleward increase. Systematic differences are found between the climatological values from Isemer and Hasse (1985) and the climatological values from Lindau and Hasse (1997). The latter values are higher than the previous values. The differences between both results are larger than $20 \mathrm{~W} \mathrm{~m}^{-2}$ at midand high latitudes. To understand the differences with the other results, we analyzed the simulated $L_{\text {net }}$ for clear-sky cases from the radiosonde data for October 1989. The emitted longwave radiation from the sea surface (Fig. 7a) decreases generally with latitudes due to the decreasing sea surface temperature (Fig. 7b), but the downwelling radiation (Fig. 7c) from the atmosphere, which is mainly related to the water vapor content of the atmosphere (Fig. 7d), decreases even faster. The emitted longwave radiation from the ocean surface varies from 300 to $480 \mathrm{~W} \mathrm{~m}^{-2}$ with latitudes, while the downward longwave radiation changes from about 190 to $430 \mathrm{~W} \mathrm{~m}^{-2}$ with latitude. Thus, $L_{\text {net }}$ increases slightly from the midlatitudes to the high latitudes (Fig. 7e). This only partly supports the argument of the poleward increase of $L_{\text {net }}$. The question remains, however, as to how clouds change this behavior.

We finally compare our results with another satellitederived distribution of $L_{\text {net }}$ (Fig. 8), which is plotted from the surface radiation dataset of Darnell et al. (1992). Darnell et al. (1992) have computed $L_{\text {net }}$ using the ISCCP C1 dataset for October 1989. Both results agree in general, but striking differences occur over the Atlantic Ocean off the coast of southern Africa and in the regions over the maritime stratocumulus off the west coasts of North and South America. In those areas, our values are larger than the values of Darnell et al. (1992). Stephens et al. (1994) have compared TOVS column water with coincident radiosonde data. They have found that TOVS column water over the Atlantic ocean off the coast of southern Africa mentioned above is about $10 \mathrm{~kg} \mathrm{~m}^{-2}$ higher than radiosonde data. The difference of $10 \mathrm{~kg} \mathrm{~m}^{-2}$ of column water results in about a difference of $35 \mathrm{~W} \mathrm{~m}^{-2}$ of $L_{\text {net }}$ for clear-sky cases over those areas based on our model results. But, this could not explain the lower $L_{\text {net }}$ from Darnell et al. (1992), because it is not well known how clouds influence $L_{\text {net }}$ over those areas. In fact, the results from Darnell et al. (1992) agree with the climatogical vaules of Isemer and Hasse (1985). Our results are close to the climatological distribution from Lindau and Hasse (1997). All those 


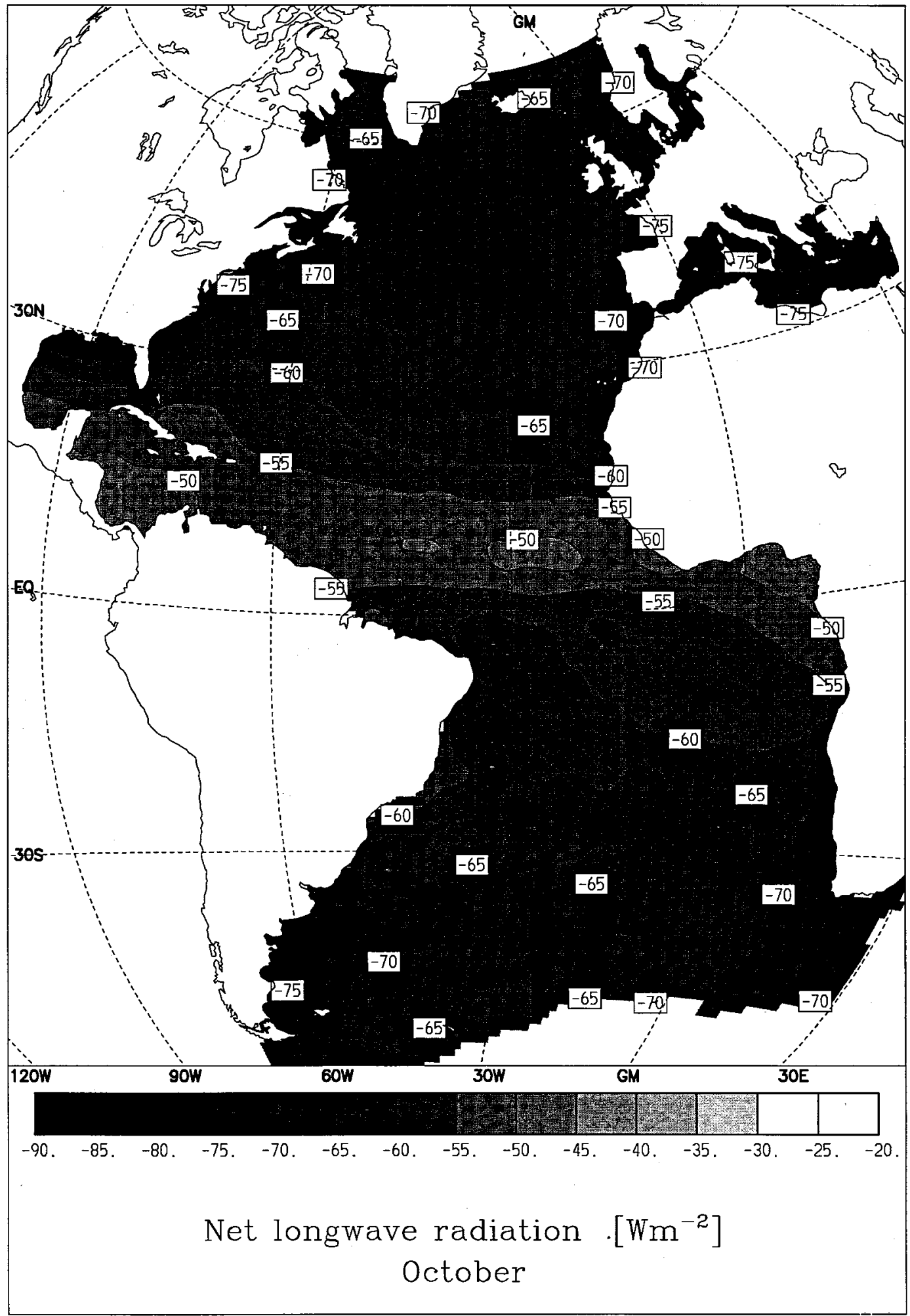

FIG. 6b. Climatological distribution of $L_{\text {net }}\left(\mathrm{W} \mathrm{m}^{-2}\right)$ for October over the Atlantic Ocean (Lindau and Hasse 1997). 

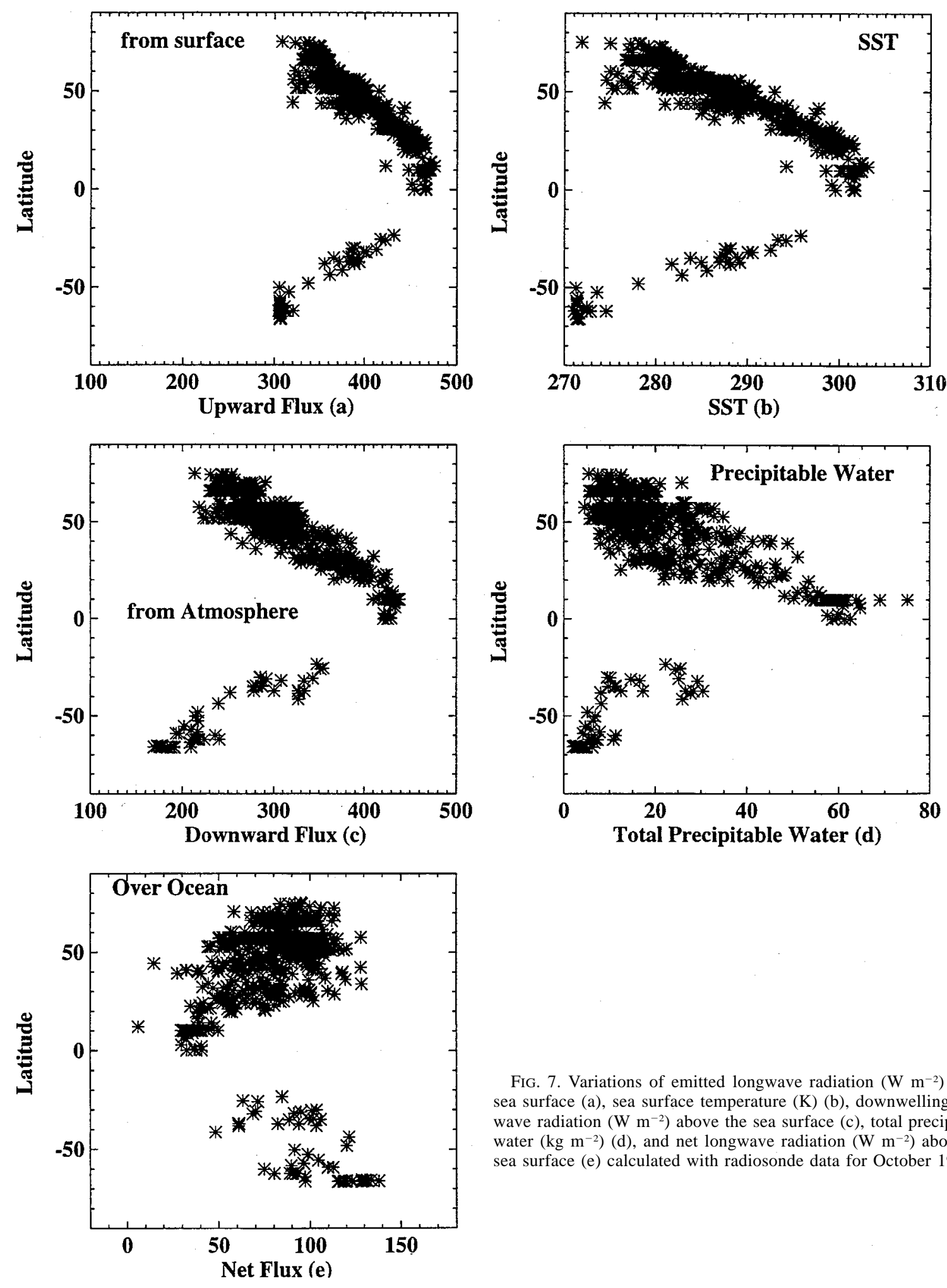

FIG. 7. Variations of emitted longwave radiation $\left(\mathrm{W} \mathrm{m}^{-2}\right)$ at the sea surface (a), sea surface temperature $(\mathrm{K})(\mathrm{b})$, downwelling longwave radiation $\left(\mathrm{W} \mathrm{m}^{-2}\right)$ above the sea surface $(\mathrm{c})$, total precipitable water $\left(\mathrm{kg} \mathrm{m}^{-2}\right)(\mathrm{d})$, and net longwave radiation $\left(\mathrm{W} \mathrm{m}^{-2}\right)$ above the sea surface (e) calculated with radiosonde data for October 1989. 


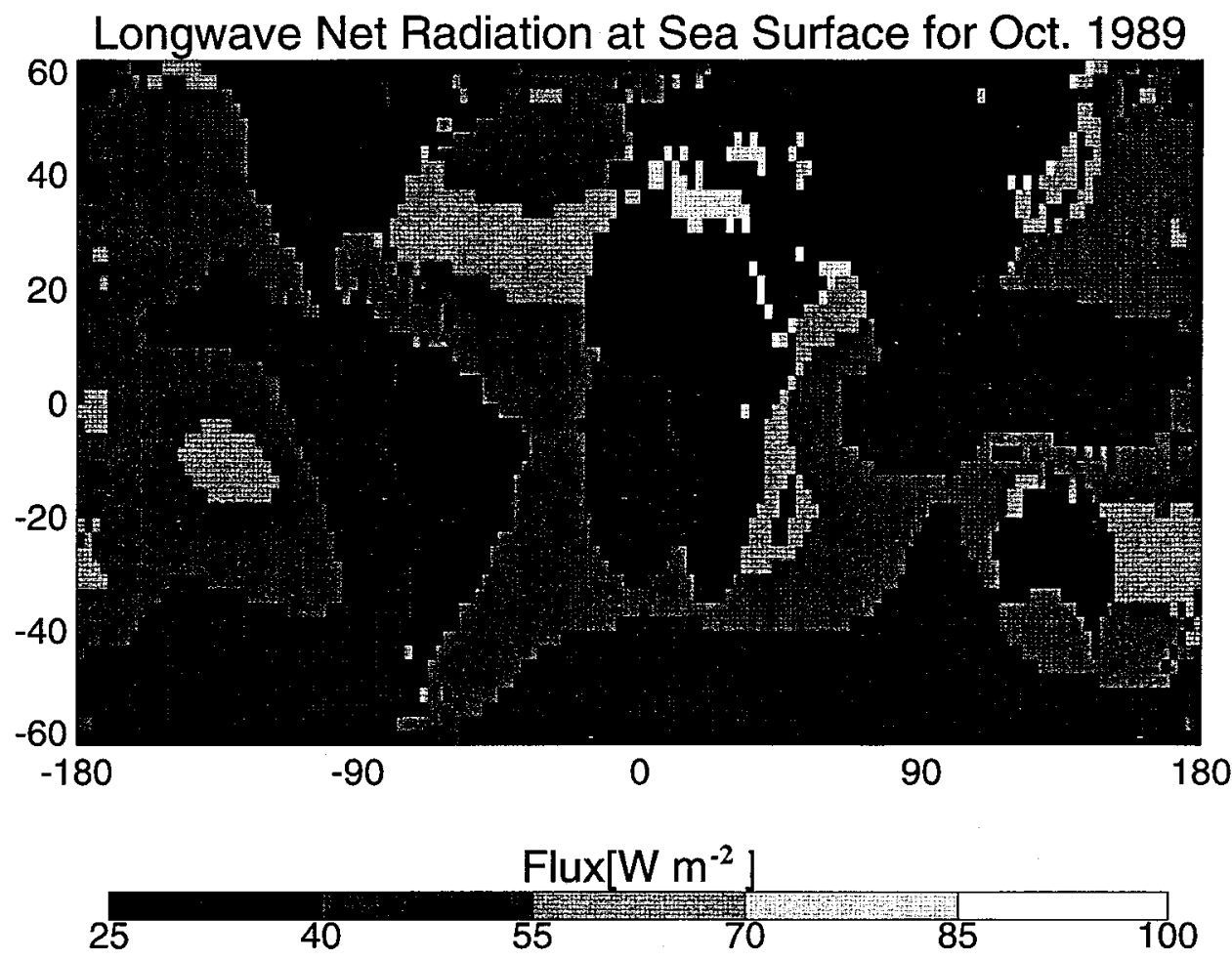

FIG. 8. Global monthly mean values of $L_{\text {net }}\left(\mathrm{W} \mathrm{m}^{-2}\right)$ over oceanic areas for October 1989. The figure is reproduced from surface radiation dataset of Darnell et al. (1992).

results are reasonable considering the uncertainties of the estimation of $L_{\text {net }}$. We should also mention that large differences between both results also occur in the high latitudes of both hemispheres.

\section{Discussion and conclusions}

We have shown that passive microwave measurements from satellites over oceanic areas do contain information about the net longwave flux at the sea surface. Radiative transfer calculations indicate that the relation between $L_{\text {net }}$ and the SSM/I TB is nonlinear. A retrieval algorithm is derived to calculate $L_{\text {net }}$ on the basis of a neural network, which suggests an accuracy of about 5 $\mathrm{W} \mathrm{m} \mathrm{m}^{-2}$. There is not yet a comprehensive in situ validation in this approach. For such a validation hundreds of in situ measurements are at least required. A comparison with a very limited set of measurements provides some proof for clear-sky cases, but a reasonable comparison for cloudy cases was not possible due to the large variability and the limited validation dataset. Comparisons with other published results based on ship reports and satellites made us confident in the reliability of our algorithm. The differences between the values of Darnell et al. (1992) and our values are generally less than $15 \mathrm{~W} \mathrm{~m}^{-2}$. We found a poleward increase of $L_{\mathrm{net}}$, that is contrary to the long-term climatological values of Isemer and Hasse (1985). But, it agrees with the results of Lindau and Hasse (1996). Discrepancies and questions remain, however, concerning the values obtained for the high latitudes.

Infrared radiometers have a better resolution to account for the spatial inhomogenity of clouds. Microwave radiometer can extract information under clouds for homogeneous cases. Combination of both radiometer types could improve the accuracy of the estimation of $L_{\text {net }}$ for cloudy cases.

Acknowledgments. We wish to thank Ralf Lindau for many helpful discussions. We wish also to thank N. A. Ritchey for providing results calculated from the ISCCP $\mathrm{C} 1$ dataset. The radiosonde data used in this study were provided by the German Weather Service (DWD).

\section{REFERENCES}

Anderson, E. R., 1952: Energy budget studies. U.S. Geol. Surv. Circ., 229, 71-119.

Bauer, P., and P. Schluessel, 1993: Rainfall, total water, ice water, and water vapor over sea from polarized microwave simulations and Special Sensor Microwave/Imager data. J. Geophys. Res., 98, $20737-20759$.

Bignami, F., R. Santoleri, M. Schiano, and S. Marullo, 1991: Net longwave radiation in the western Mediterranean Sea. Poster Session at the 20th General Assembly of the International Union of Geodesy and Geophysics, Vienna, Austria, IAPSO.

Budyko, M. I., 1974: Climate and Life. International Geophysics Series, Vol. 18, Academic Press, 508 pp.

Chen, K. S., W. L. Kao, and Y. C. Tzeng, 1995: Retrieval of surface 
parameters using dynamic learning neural network. Int. J. Remote Sens., 16, 801-809.

Crewell, S., E. Ruprecht, and C. Simmer, 1991: Latent heat flux over the North Atlantic Ocean-A case study. J. Appl. Meteor., 30, $1627-1635$

Darnell, W. L., W. F. Staylor, S. K. Gupta, N. A. Ritchey, and A. C. Wilber, 1992: Seasonal variation of surface radiation budget derived from International Satellite Cloud Climatology Project C1 data. J. Geophys. Res., 97, 15 741-15 760.

Fung, I. Y., D. E. Harrison, and A. A. Lacis, 1984: On the variability of the net longwave radiation at the ocean surface. Rev. Geophys., 22, 177-193.

Gilman, C., and C. Carrett, 1994: Heat flux parameterizations for the Mediterranean Sea: The role of atmospheric aerosols and constraints from the water budget. J. Geophys. Res., 99, 5119-5134.

Goodberlet, M. A., C. I. Swift, and I. C. Wilheon, 1990: Ocean surface wind speed measurements of the special microwave imager (SSM/I). IEEE Trans. Geosci. Remote Sens., GE-28, 823-827.

Greenwald, T., G. L. Stephens, T. H. Vonder Haar, and D. L. Jackson, 1993: A physical retrieval of cloud liquid water over the global oceans using Special Sensor Microwave/Imager (SSM/I) observations. J. Geophys. Res., 98, 18 471-18 488.

Gupta, S. K., 1989: A parameterization for longwave surface radiation from sun-synchronous satellite data. J. Climate, 2, 305-320.

Haferman, J. L., E. N. Anagnostou, D. Tsintikidis, W. F. Krajewski, and T. F. Smith, 1996: Physically based satellite retrieval of precipitation using a 3D passive microwave radiative transfer model. J. Atmos. Oceanic Technol., 13, 832-850.

Hennings, D., M. Quante, and R. Sefzig, 1990: International Cirrus Experiment 1989 Field Phase Report, 129 pp. [Available from Institute of Geophysics and Meteorology, University of Cologne, Cologne, Germany.]

Hertz, J., A. Krogh, and R. G. Palmer, 1991: Introduction to the Theory of Neural Computation. Addison-Wesley, 327 pp.

Isemer, H.-J., and L. Hasse, 1985: The Bunker Climate Atlas of the North Atlantic Ocean. Vol. 1, Observations, Springer-Verlag, $218 \mathrm{pp}$.

Karstens, U., C. Simmer, and E. Ruprecht, 1994: Remote sensing of cloud liquid water. Meteor. Atmos. Phys., 54, 157-171.

Liebe, H. J., 1985: An updated model for millimeter wave propagation in moist air. Radio Sci., 20, 1069-1089.

Lindau, R., and L. Hasse, 1997: COADS Climate Atlas of the Atlantic Ocean. Springer-Verlag, in press.
Liou, K. N., 1980: An Introduction to Atmospheric Radiation. Academic Press, 392 pp.

_ 1986: Influence of cirrus clouds on weather and climate processes: A global perspective. Mon. Wea. Rev., 114, 1167-1199.

Liu, G., and J. A. Curry, 1992: Retrieval of precipitation from satellite microwave measurement using both emission and scattering. $J$. Geophys. Res., 97, 9959-9974.

Liu, Q., and E. Ruprecht, 1996: A radiative transfer model: Matrix operator method. Appl. Opt., 35, 4229-4237.

Petty, G. W., 1994: Physical retrievals of over-ocean rain rate from multichannel microwave imagery. Part II: Algorithm implementation. Meteor. Atmos. Phys., 54, 101-122.

Ramanathan, V., 1986: Scientific use of surface radiation budget data for climate studies. Position Paper in NASA RP-1169, $132 \mathrm{pp}$.

Schmetz, J., 1986: An atmospheric-correction scheme for operational application to METEOSAT infrared measurements. ESA, 10, $145-159$.

_ 1 1989: Towards a surface radiation climatology: Retrieval of downward irradiances from satellites. Atmos. Res., 23, 287-321.

Simmer, C., 1994: Satellitenfernerkundung Hydrologischer Parameter der Atmosphäre mit Mikrowellen. Verlag, $313 \mathrm{pp}$.

Smith, W. L., and H. M. Woolf, 1983: Geostationary satellite sounder (VAS) observations of longwave radiation flux. Paper Presented at the Satellite Systems to Measure Radiation Budget Parameters and Climate Change Signal, Igls, Austria, International Radiation Commission.

Stephens, G. L., D. L. Jackson, and J. J. Bates, 1994: A comparison of SSM/I and TOVS column water data over the global oceans. Meteor. Atmos. Phys., 54, 183-201.

Tsang, L., Z. X. Chen, S. Oh, R. J. Marks, and A. T. C. Chang, 1992: Inversion of snow parameters from passive microwave remote sensing measurements by a neural network trained with a multiple scattering model. IEEE Trans. Geosci. Remote Sens., 30, $1015-1024$.

Weng, F. Z., and N. Grody, 1994: Retrieval of cloud water using the Special Sensor Microwave Imager (SSM/I). J. Geophys. Res., 99, 25 535-25 551.

Wentz, F. J., 1992: Measurement of oceanic wind vector using satellite microwave radiometers. IEEE Trans. Geosci. Remote Sens., 30, 960-972.

Wisler, M. M., and J. P. Hollinger, 1977: Estimation of marine environmental parameters using microwave radiometric remote sensing systems. N.R.L. Memo. Rep. 3661, 27 pp.

Zhi, H., and Harshvardhan, 1993: A hybrid technique for computing the monthly mean net longwave surface radiation over oceanic areas. Theor. Appl. Climatol., 47, 65-79. 